DOI 10.17516/1997-1370-0779

УДК 504.03

\title{
Environmental Aspects of the new wave of raw materials industrialization in Asian Russia
}

\author{
Vadim M. Gilmundinov* and Tatyana O. Tagaeva \\ Institute of Economics and Industrial Engineering of SB RAS \\ Novosibirsk State University \\ Novosibirsk, Russian Federation
}

Received 25.05.2021, received in revised form 15.06.2021, accepted 28.06.2021

\begin{abstract}
The paper examines the problems of assessing the long-term impact of intensive exploitation of natural resources on the environment of a large region. Data for empirical study obtained from information of Rosstat and Annual State Reports «On the state and protection of the environment of the Russian Federation». The vast territory of Asian Russia was chosen as the object of research. The results indicate a significant increase in environmental problems at each stage of industrial development in this region. These problems are especially acute in connection with the entry of Asian Russia into the next wave of accelerated industrialization of raw materials, characterized, first of all, by a significant expansion of projects for the extraction and processing of solid minerals and hydrocarbons to new mostly undeveloped territories. This, taking into account the already accumulated environmental problems, makes additional requirements for the substantiation of plans to accelerate the socio-economic development of the region and the launch of new raw materials projects, bringing to the first place not only economic and strategic aspects, but also issues of environmental safety. This, in turn, requires not only constant monitoring of the state of the environment and protection activities of business entities, increasing the reliability and completeness of the results obtained on its basis, but also assessing the compliance of the existing institutional environment with the tasks of eliminating environmental problems accumulated in the region and reducing the negative anthropogenic impact on the environment. At the same time, the results of the analysis of both current approaches to statistical observation in this area and environmental mechanisms indicate the presence of significant imperfections in them. In this regard, it is necessary to improve the institutional mechanisms for regulating environmental protection in order to increase the sustainability of the region's development.
\end{abstract}

Keywords: sustainable development, Asian Russia, emissions of air pollutants, water pollution, production and consumption waste, environmental monitoring, environmental policy.

\footnotetext{
(C) Siberian Federal University. All rights reserved

* Corresponding author E-mail address: gilmundinov@mail.ru ORCID: 0000-0002-1991-0114 (Gilmundinov); 0000-0002-9467-6436 (Tagaeva)
} 
This study was funded by the Russian Federation represented by the Ministry of Science and Higher Education of Russia in the framework of a large-scale research project «Socio-Economic Development of Asian Russia on the Basis of Synergy of Transport Accessibility, System Knowledge of the Natural Resource Potential, Expanding Space of Inter-Regional Interactions», Agreement no. 075-15-2020-804 dated 02.10.2020 (grant № 13.1902.21.0016).

Research area: economics.

Citation: Gilmundinov V.M., Tagaeva T.O. (2021). Environmental aspects of the new wave of raw materials industrialization in Asian Russia. J. Sib. Fed. Univ. Humanit. Soc. Sci., 14(7), 998-1007. DOI: $10.17516 / 1997-1370-0779$.

\title{
Экологические аспекты новой волны сырьевой индустриализации Азиатской России
}

\section{B.М. Гильмундинов, Т.О. Тагаева}

Институт экономики и организации промышленного производства СО РАН

Новосибирский государственный университет

Российская Федерачия, Новосибирск

\begin{abstract}
Аннотация. В статье исследуются проблемы оценки длительного воздействия интенсивной эксплуатации природных ресурсов на окружающую среду крупного региона. Для исследования использована информация Росстата, ежегодных Государственных докладов «О состоянии и об охране окружающей среды РФ». В качестве объекта исследования выбрана обширная территория Азиатской России. Проведенный анализ указывает на значительное нарастание экологических проблем на каждом этапе ее промышленного освоения. Особую остроту данные проблемы вызывают в связи с вступлением Азиатской России в очередную волну ускоренной сырьевой индустриализации, характеризующейся, в первую очередь, существенным расширением проектов по добыче и переработке твердых полезных ископаемых и углеводородного сырья на новые ранее преимущественно не освоенные территории. Это с учетом уже накопившихся экологических проблем предъявляет дополнительные требования к обоснованию планов по ускорению социально-экономического развития региона и запуску новых сырьевых проектов, выводя на первое место не только экономические и стратегические аспекты, но и вопросы экологической безопасности. В свою очередь, это требует не только постоянного мониторинга состояния окружающей среды и природоохранной деятельности хозяйствующих субъектов, повышения достоверности и полноты получаемых на его основе результатов, но и оценки соответствия сложившейся институциональной среды задачам по ликвидации накопленных в регионе экологических проблем и снижению негативного антропогенного воздействия на окружающую среду. В то же время результаты анализа как действующих в России подходов к статистическому наблюдению в этой области, так и природоохранных механизмов указывают на наличие в них значительных несовершенств. В этой связи необходимо совершенствование институциональных механизмов регулирования природоохранной деятельности в целях повышения устойчивости развития региона.
\end{abstract}


Ключевые слова: устойчивое развитие, Азиатская Россия, выбросы загрязняющих атмосферу веществ, загрязнение водных ресурсов, отходы производства и потребления, мониторинг состояния окружающей среды, природоохранная политика.

Статья подготовлена по результатам исследования, проводимого при финансовой поддержке Министерства науки и высшего образования Российской Федерации в рамках крупного научного проекта «Социально-экономическое развитие Азиатской России на основе синергии транспортной доступности, системных знаний о природно-ресурсном потенциале, расширяющегося пространства межрегиональных взаимодействий», Соглашение № 075-15-2020-804 от 02.10.2020 (грант № 13.1902.21.0016).

Научная специальность: 08.00.05 - экономика и управление народным хозяйством.

\section{Введение}

История хозяйственного освоения Азиатской России, объединяющей территории Сибирского и Дальневосточного федеральных округов, а также Тюменской области, характеризуется важной отличительной особенностью. Так, если мировой опыт освоения нового пространства людьми, в особенности на ранних этапах развития человеческой цивилизации, так или иначе связан преимущественно с поиском новых территорий, комфортных для проживания и ведения экономической деятельности, то в случае Азиатской России главной мотивацией для ее освоения выступал ее богатый природно-ресурсный потенциал даже несмотря на суровые природноклиматические условия на большей ее части.

Если на начальных стадиях освоения интерес представляли главным образом ресурсы лесного хозяйства и охоты, то по мере индустриализации мировой экономики четко обозначилась направленность развития данного региона на усиление сырьевой специализации. Колоссальные масштабы освоения ресурсов региона и соображения национальной безопасности потребовали комплексного подхода к освоению данной территории, численность постоянно проживающего населения которой составила на начало 2020 г. 29 млн человек. Суровые природно-климатические условия и соображения экономической целесообразности предопределили вы- сокую концентрацию обрабатывающей промышленности в городах. В то же время восприятие Азиатской России как бескрайней территории с неиссякаемым природно-восстановительным потенциалом не способствовало бережливому отношению к окружающей среде. В результате сложилась ситуация, когда экологические проблемы накапливались десятилетиями, при этом не предпринималось действенных шагов к их разрешению. Остроту данной проблемы подчеркивает накопленный износ технологического оборудования и сооружений, в том числе по хранению опасных отходов. Данные обстоятельства ведут к тому, что действие неблагоприятных природно-климатических условий усиливается неблагоприятной ситуацией с состоянием окружающей среды, что оказывает значительное негативное влияние на привлекательность Азиатской России как среды проживания и пространства для экономической деятельности, что, в свою очередь, усиливает миграционные настроения населения, затрудняя формирование на данной территории современной высокотехнологичной экономики.

Новая волна сырьевой индустриализации Азиатской России, обусловленная главным образом ожиданиями формирования нового суперцикла на мировых сырьевых рынках, разворачивается, таким образом, на фоне накопившихся значительных экологических проблем. Это предъявляет повышенные требования как к мониторингу 
состояния окружающей среды и предупреждению потенциальных угроз экологической безопасности, так и к реализации масштабных мер по ликвидации накопленных загрязнений. Вместе с тем основными хозяйствующими субъектами, оказывающими значительное воздействие на окружающую среду Азиатской России, выступают частные компании, что делает особо актуальным вопрос совершенствования природоохранного законодательства. Отдельно стоит проблема обеспечения надлежащего контроля за недропользователями в новых труднодоступных или экстремальных по природно-климатическим условиям районах промышленного освоения запасов полезных ископаемых, особенно в Арктике и Восточной Сибири.

Отметим, что в современной научной литературе накоплен богатый опыт разработки подходов, актуальных для решения указанных задач. Так, за несколько десятилетий активного развития исследований в области устойчивости развития разработаны и успешно применены для практических расчетов многие серии статистических индикаторов, отражающих взаимное влияние антропогенной нагрузки на природную среду и параметров развития экономики (Pearce, Atkinson, 1993; Kubiszewski et al., 2013; Barrington-Leigh, Escande, 2018; Hák et al., 2018; Fox, Erikson, 2020). Большой интерес вызывает активно развивающаяся концепция «зеленой» экономики. «Зеленые» тенденции являются трендом развития современной экономики и требуют новых исследований, что отмечается в постановочных работах (Porfiriev, 2016; Bobylev, Solovyeva, 2017; Danilov-Danilyan, Piskulova, 2015; Glazyrina, Zabelina, 2010). Проблемы количественной оценки устойчивости развития как на уровне России в целом, так и отдельных ее регионов достаточно широко обсуждаются в литературе. При этом значительное внимание уделяется проведению таких оценок именно на региональном уровне. Разработаны и широко используются методики оценки международно-признанных индикаторов устойчивости для различных регионов и макрорегионов страны (Bobylev et al., 2012; Glazyrina et al., 2010; Pyzheva, 2020; Ryumina, 2013; Korobitsyn, 2015; Pyzheva et al., 2021). Наконец, немаловажной проблемой остаются ограничения использования российской макроэкономической и отраслевой статистики (Bessonov, 2015; Shirov, 2020; Pyzhev et al., 2021).

\section{Постановка задачи}

Полный спектр обозначенных выше проблем требует достаточно широкого круга исследований. В рамках данного исследования основной акцент сделан на вопросах оценки соответствия сложившихся тенденций в Азиатской России принципам устойчивого развития, а также соответствия действующей в России природоохранной системы задачам надлежащего мониторинга и улучшения качества окружающей среды.

Приоритет развития Азиатской России как крупного научного, образовательного и промышленного центра критически важен для достижения стратегических целей социально-экономического развития России. Это объясняется наличием значительного потенциала Сибири и Дальнего Востока, который может быть использован не только в ускорении собственного развития этих территорий, но и в обеспечении устойчивого экономического роста России в целом. Этот потенциал включает удобное географическое положение в непосредственной близости к самому большому в мире и динамично развивающемуся рынку Азиатско-Тихоокеанского региона, наличие крупнейших в мире запасов природных ресурсов, обилие туристско-рекреационных объектов, транспортных узлов и магистралей, развитую производственную и научнообразовательную сферы.

Однако имеющийся потенциал Азиатской России до сих пор эффективно не используется, наряду с преимуществами существуют достаточно серьезные вызовы и угрозы, а развитие региона далеко от «устойчивого». Наблюдается значительное отставание от среднероссийского уровня по ключевым социальным показателям 
(ожидаемой продолжительности жизни, отношению среднедушевых доходов к прожиточному минимуму, обеспеченности транспортной, финансовой и социальной инфраструктурами и др.). Регион сталкивается с вывозом капитала и оттоком населения в европейскую часть России и за границу. Российские наилучшие доступные технологии допускают превышение образования загрязняющих веществ на многих производствах по сравнению с мировыми нормами. Наконец, значительную проблему представляет состояние окружающей среды Азиатской России.

\section{Загрязнение атмосферного воздуха}

Согласно официальным данным Росстата, в 2018 г. по сравнению с 2008 г. выбросы загрязняющих атмосферу веществ в России сократились на 4,8 \%, при этом в Азиатской России - на 17,0 \%. Однако достоверность приведенных данных вызывает сомнения. Так, в 2013 г. изменилась методика учета выбросов от передвижных источников (Распоряжение Росприроднадзора от 01.11.2013 N6-p), данные по которым стал предоставлять Росприроднадзор. До этого действовали методологические рекомендации, разработанные ОАО «НИИ Атмосфера». Новая методика не учитывает многие параметры (расход топлива автомобильным транспортом и его качество, специфику населенных пунктов (пробег, пробки, зимний обогрев), изменение структуры автомобилей каждого экологического класса). Так, в результате пересчета показателей по новой методике в 2010 г. по сравнению с 2009 г. в Азиатской России, несмотря на рост автопарка, на 6,5 \% сократились выбросы от передвижных источников. В 2020 г. российская статистика опять перешла на новую методику (с учетом требований Таможенного Союза и ОЭСР к экологическим классам автомобилей и качеству и типам топлива), согласно которой выбросы от передвижных источников в 2019 г. в целом по России сократились в 3 раза от уровня выбросов 2018 г. В свою очередь, информация о выбросах в атмосферу, отходящих от стационарных источников, составляется на основе отчетов о выбросах, предоставляемых самими предприятиями, которые заинтересованы в занижении их объемов для уменьшения платежей за негативное воздействие на окружающую среду.

В то же время проверить достоверность отчетных данных не представляется возможным из-за устаревшей системы мониторинга и недостатка станций для наблюдения за состоянием атмосферы. Например, в 2018 г. в Ямало-Ненецком автономном округе и в Еврейской автономной области имелось всего по одной станции, а в Республике Алтай мониторинг атмосферного воздуха не проводится вообще'. Многие станции были установлены более 10 лет назад, когда источники выбросов, массовая застройка, схемы автодорог были совсем другими. В современных условиях посты наблюдений за состоянием атмосферы часто не фиксируют максимальные залповые выбросы или не могут определить ответственные за них предприятия.

Наихудшая ситуация с загрязнением атмосферного воздуха наблюдается в Сибирском федеральном округе (СФО). По данным Росстата, выбросы в атмосферу, исходящие от стационарных источников и автотранспорта, в СФО составляют больше $20 \%$ суммарного объема российских выбросов. Среднедушевые выбросы (403 кг на человека в 2018 г.) почти в 2 раза превышают среднероссийский показатель (220 кг). Больше всего на душу населения выбросов от стационарных источников производится в Ханты-Мансийском AO (827,7 кг на человека в год), в ЯмалоНенецком АО $(1371,5)$, Красноярском крае $(806,9)$, Чукотском AO (460) при среднегодовых душевых выбросах в России в целом, равных 116,5 кг на человека в год.

В 2018 г. по сравнению с 2010 г. в части регионов наблюдается существенный рост выбросов от стационарных источников (в Тюменской области (без ХМАО и ЯНАО) - на 62,1 \%, Хакасии - на 10,9 \%, Иркутской области - на 7,3 \%, Якутии -

\footnotetext{
1 Государственный доклад «О состоянии и об охране окружающей среды Российской Федерации в 2018 году» (2019). М.: Минприроды России; НПП «Кадастр». 844 с.
} 
на 59,1 \%, Камчатского края - на 10,3 \%, в Магаданской области - на 13,8 \%, в Чукотском автономном округе - на 7,4\%). В большинстве регионов увеличились объемы выбросов от передвижных источников (сильнее всего в Республике Алтай на $23,4 \%$, в Бурятии - на 47,9 \%, в Хабаровском крае - на 24,8 \%).

По данным докладов «О состоянии и об охране окружающей среды Российской Федерации», ежегодно в 10-15 городах СФО фиксируется превышение допустимых лимитов загрязнения воздушного бассейна в 10 и более раз (такое загрязнение характеризуется как высокое). В 2018 г. в 26 городах СФО фиксировалось высокое и очень высокое загрязнение атмосферного воздуха ${ }^{2}$ (в 2019 г. в 22 городах). Более $55 \%$ городского населения СФО (более 9 млн человек) дышат воздухом низкого качества (в республиках Тыва и Хакасия, в Алтайском и Красноярском краях, в Иркутской и Новосибирской областях - более 60 \% населения). Особенно неблагоприятная экологическая ситуация сложилась в Красноярске, Кемерово, Новокузнецке, Норильске, Братске, Ангарске. По оценке экспертов Института Блэксмита ${ }^{3}$, Норильск входит в десятку самых грязных городов мира. На его долю приходится $10 \%$ всех российских атмосферных выбросов и $2 \%$ мировых выбросов углекислого газа. Также чрезвычайно загрязненный воздух наблюдается в Красноярском крае. По данным рейтинга IQAir компании AirVisual ${ }^{4}$ (данные за февраль 2020 г.), Красноярск стал первым среди крупнейших городов мира по уровню загрязнения воздуха, обойдя индийский

\footnotetext{
2 Уровень загрязнения атмосферы считается очень высоким при ИЗА, равным или больше 14. ИЗА (комплексный индекс загрязнения атмосферы) рассчитывается по значениям среднегодовых концентраций пяти загрязняющих веществ.

3 Blacksmith Institute - научно-исследовательский институт (основан в 1999 г., расположен в Нью-Йорке), занимающийся проблемами экологии.

4 AirVisual - международная коммерческая компания (США, Швейцария, Китай, существует с 2015 г.), производящая мониторы качества воздуха, основанные на новейших разработках в области лазерных сенсоров, разрабатывает крупнейшую в мире базу данных о качестве воздуха в городах мира.
}

город Мумбаи. Лишь в семи городах СФО, в которых ведется наблюдение за состоянием атмосферы, загрязнение воздуха классифицировалось как низкое 5

В Дальневосточном федеральном округе (ДВО) с высоким и очень высоким загрязнением атмосферного воздуха насчитывалось в 2018 г. 10 городов и в 2019 г.- 11 городов. Среди них: Гусиноозерск, Селенгинск, Улан-Удэ, Уссурийск, Чегдомын, Чита, Южно-Сахалинск. Доля населения, проживающего в неблагоприятных экологических условиях, составляет $25 \%$ населения ДВО (более 2 млн человек). В Бурятии в условиях плохого качества атмосферы проживал в 2018 г. 81 \% населения, в Еврейской $\mathrm{AO}-65 \%$, в Забайкальском крае, Амурской и Сахалинской областях - почти половина населения.

Во многих городах повышаются среднегодовые концентрации загрязняющих атмосферу веществ относительно ПДК. В то же время в последние годы законодательно были повышены ПДК загрязняющих атмосферу веществ (например, для формальдегида в 2014 г. в 3,3 раза, для фенола в 2015 г. в 2 раза, а в 2017 г. еще в 1,7 раза, с 1999 по 2017 г. максимально разовая ПДК для метилмеркаптана была повышена в 660 раз) ${ }^{6}$. Таким образом, статистика концентрации загрязняющих атмосферу веществ не в полной мере отражает реальную динамику уровня загрязнения атмосферного воздуха.

\section{Загрязнение водных ресурсов}

Основным фактором загрязнения поверхностных вод является сброс загрязненных сточных вод. По данным Росводресурса, за 2018 г. общий объем сброса загрязненных сточных вод в Азиатской России составил 11,8 млрд м ${ }^{3}$ - почти $20 \%$ от общероссийского сброса. Вместе с тем с 2010 по 2018 г.

\footnotetext{
5 Список городов России с наибольшим уровнем загрязнения атмосферного воздуха (2020) // Федеральная служба по гидрометеорологии и мониторингу окружающей среды. - [http://voeikovmgo.ru/?id=681\&lang=ru]

6 Нормативы ПДК и их изменения // Информационный портал «ЭкоДело». 11 октября 2019 г.- [https://ecodelo.org/ rossiyskaya_federaciya/44771-normativy_pdk_i_ih_izmeneniya]
} 
объемы общего сброса загрязненных сточных вод снижаются практически во всех регионах (кроме Ханты-Мансийского автономного округа, Алтайского края и Томской области) и в крупных загрязняющим водные ресурсы городах.

В целом ситуация с водными ресурсами в регионах азиатской части России сопоставима со среднероссийской: среднедушевые объемы сброса загрязненных сточных вод в СФО, ДВО и в среднем по России составляют около 90 куб м на человека, в регионах Тюменской области - меньше (около 50 куб м на человека). Однако основные очистные сооружения в Азиатской России вводились в действие еще в советское время и являются, как правило, технически устаревшими. Система очистки нуждается в регулярном ремонте и замене, однако региональные бюджеты и бюджеты предприятий не позволяют обеспечивать должную очистку сбросов. Ситуация осложняется тем, что многие малые предприятия находятся в частной собственности и не имеют возможности очищать стоки (эти загрязненные сточные воды статистически не фиксируются).

Также нужно иметь в виду, что для водных ресурсов были законодательно повышены нормативы предельно допустимого содержания (ПДС) многих загрязняющих веществ в составе сточных вод, которое ранее позволяло отнести их к категории «загрязненных». Таким образом, собираемые в рамках государственной статистики данные о сбросах загрязненных сточных вод в бассейны рек не могут быть достаточным основанием для оценки изменения качества вод. Так, четыре крупные реки Азиатской России (Енисей, Амур, Обь и Колыма) остаются загрязненными, на их долю приходится половина всех случаев зафиксированного экстремально высокого и высокого загрязнения российских рек в 2018 г. Эти реки входят в десятку самых грязных рек России.

Наблюдаются экологические проблемы в прибрежных водах морей и океанов, омывающих территорию Азиатской России. К примеру, максимальное содержание углеводородных соединений в водах Авачинской губы (Камчатка) в 2017 и 2018 гг. составило 4 ПДК. Среднегодовое значение концентрации фенолов в 2018 г. равнялось 2,0 ПДК, а максимальное - 20 ПДК. Отдельную проблему представляет загрязнение озера Байкал, сталкивающегося с угрозой экологической катастрофы от неочищенных вод Байкальского ЦБК.

\section{Отходы производства и потребления}

Ситуация с накоплением отходов в Азиатской России сложилась катастрофическая. За последнее десятилетие объем образованных отходов вырос в Азиатской России в 2,2 раза (в целом по РФ - на $87 \%$ ). Сибирский федеральный округ является абсолютным лидером по количеству образованных отходов в России: в 2018 г. объем образованных отходов составил $66,2 \%$ от общего количества по стране. Такой крупный объем отходов связан с активной добычей полезных ископаемых, а также с образованием большого количества вскрышных пород, которые являются отходом V класса опасности и объем которых в 2018 г., по данным Росприроднадзора, составил около 99 \% от общего объема образования отходов в СФО. Среднедушевое образование отходов в СФО более чем в 5 раз превышает средний российский уровень, в ДВО - более чем в 3 раза. Больше всего отходов на душу населения (более 400 т на человека в год) образуется в Хакасии, в Якутии, Кемеровской и Магаданской областях, Чукотском автономном округе.

Наибольшую долю в регионах занимают производственные отходы (более 90 \%), общий объем накопления которых в Азиатской России составляет десятки миллиардов тонн. Во время разработки месторождений, а также переработки и обогащения полезных ископаемых на прилегающих к предприятиям территориях накапливаются твердые отходы добычи (отвалы, окисленные руды, илы в прудах нейтрализации рудничных вод), хвосты (отходы обогащения полезных ископаемых, имеющие минимальное содержание полез- 
ного компонента - так называемые пустые породы), отходы металлургической (шлаки, золы и др.) и гидрометаллургической (шламы) переработки. Данные отходы нарушают естественные биогеохимические циклы, занимают значительные территории для складирования, загрязняют вредными и токсичными веществами, пылью, газообразными выделениями атмосферу, почву, поверхностные и подземные воды. Особую экологическую угрозу несут хвостохранилища (шламохранилища), многие из которых были построены до 1970-х гг., когда их экологическая опасность не была полностью осознана и нормы строительства не были строгими. В настоящее время возникают разломы на дне таких сооружений, по ним происходят утечки загрязняющих водные ресурсы веществ, также фиксируется и загрязнение атмосферного воздуха. Многие из таких хвостохранилищ расположены в черте городов и поселков. В то же время в этой сфере практически отсутствует система экологического мониторинга и предупреждения.

\section{Заключение}

К сожалению, можно сделать вывод, что сложившаяся ситуация в Азиатской России противоречит принципам устойчивого развития. В угоду экономическому развитию страдает экологическая составляющая устойчивости: крупные предприятия оказывают совокупное негативное влияние на окружающую среду. Во многих городах Азиатской России климатические и топографические условия не способствуют рассеиванию опасных примесей, что ведет к ухудшению экологической ситуации в регионах. А климат сибирских и дальневосточных регионов отличается обилием антициклонов, которые препятствуют рассеиванию веществ, поднимающихся в атмосферу. Значительную проблему представляют накопленные отходы и загрязнения водных ресурсов. В то же время система мониторинга за качеством окружающей среды нуждается в существенном развитии.

Для изменения ситуации необходима институциональная перестройка условий взаимодействия общества и природы. Существующие как административные, так и экономические инструменты формирования и регулирования экологически ответственного поведения не работают. Не выполняет необходимых стимулирующих и компенсационных функций механизм платы за негативное воздействие на окружающую среду, регулярно превышаются предельно допустимые концентрации и содержание загрязняющих водные и атмосферные ресурсы веществ, тормозят реформы в сфере обращения с отходами. Необходимо совершенствовать существующие регулирующие инструменты природоохранной деятельности и вводить в практику новые механизмы, эффективно работающие в развитых странах: торговля квотами на выбросы, банки и биржи прав на загрязнение, углеродный налог и др.

Без принятия действенных мер есть вероятность того, что за счет ускоренного развития Азиатская Россия «потянет» вверх экономику России, но и «потянет» вниз экосистему не только страны, но и планеты в целом (с учетом той роли, которую играют леса, запасы пресной воды, многообразие биологических и растительных видов Азиатской России и т. д.).

\section{Список литературы}

Бессонов, В.А. (2015). Что сохранит для истории российская статистика // Вопросы экономики, 1, 125-146. DOI: 10.32609/0042-8736-2015-1-125-146.

Бобылев, С.Н., Минаков, В.С., Соловьева, С.Н., Третьяков, В.В. (2012). Эколого-экономический индекс регионов РФ. Методика и показатели расчета. Москва. РИО Новости. 150 p. - URL: [https://wwf.ru/upload/iblock/dc8/index.pdf].

Данилов-Данилян, В.И., Пискулова, Н.А. (2015). Устойчивое развитие: новые вызовы. Москва, Аспект Пресс. 336 р. 
Глазырина, И.П., Забелина, И.А., Клевакина, Е.А. (2010). Уровень экономического развития и распределение экологической нагрузки между регионами РФ // Журнал новой экономической ассоциации, 7, 70-88.

Коробицын, Б.А. (2015). Методический подход к учету истощения природных ресурсов, изменение состояния окружающей среды и человеческого капитала в валовом региональном продукте // Экономика региона, 3(43), 77-88. DOI: 10.17059/2015-3-7.

Порфирьев, Б.Н. (2016). «Зеленые» тенденции в мировой финансовой системе // ировая экономика и международные отношения, 60, 9, 5-16.

Рюмина, Е.В. (2013). Экологически скорректированный ВВП: сферы использования и проблемы оценки // Экономика региона, 4(36), 107-115. DOI: 10.17059/2013-4-10.

\section{References}

Barrington-Leigh, C., Escande, A. (2018). Measuring Progress and Well-Being: A Comparative Review of Indicators, In Social Indicators Research, 135(3), 893-925. DOI: 10.1007/s11205-016-1505-0.

Bessonov, V.A. (2015). Chto sokhranit dlya istorii rossijskaya statistika? [What Will the modern Russian Statistics have in Store for history?], In Voprosy Ekonomiki [Voprosy Ekonomiki], 1, 125-146. DOI: 10.32609/0042-8736-2015-1-125-146.

Bobylev, S.N., Minakov, V.S., Solovyeva, S. V., Tretyakov, V.V. (2012). Ekologo-ekonomicheskij indeks regionov RF. Metodika i pokazateli rascheta [Ecological and economic index of the regions of the Russian Federation. Calculation methodology and indicators]. Moscow, WWF Rossii, RIA Novosti, 150 p. - URL: [https://wwf.ru/upload/iblock/dc8/index.pdf].

Bobylev, S. N., Solovyeva, S. V. (2017). Sustainable development goals for the future of Russia. In Studies on Russian Economic Development, 28(3), 259-265. DOI: 10.1134/s1075700717030054.

Danilov-Danilyan, V.I., Piskulova, N.A. (2015). Ustojchivoe razvitie: novye vyzovy [Sustainable Development: New Challenges]. Moscow, Aspekt Press, 336 p.

Fox, M.-J. V., Erickson, J. D. (2020). Design and meaning of the genuine progress indicator: A statistical analysis of the U.S. fifty-state model. In Ecological Economics, 167, 106441. DOI: 10.1016/j.ecolecon.2019.106441.

Glazyrina, I.P., Zabelina, I.A. (2020). Jevons' paradox: do Russian environmental institutions contribute to green growth? In Journal of Siberian Federal University - Humanities and Social Sciences, 13(4), 496-506. DOI: 10.17516/1997-1370-0584.

Glazyrina, I.P., Zabelina, I.A., Klevakina, E.A. (2010). Uroven' ekonomicheskogo razvitiya i raspredelenie ekologicheskoj nagruzki mezhdu regionami RF [The level of economic development and the distribution of the environmental burden between the regions of the Russian Federation], In Zhurnal Novoj ekonomicheskoj associacii [The Journal of the New Economic Association], 7, 70-88.

Hák, T., Janoušková, S., Moldan, B., Dahl, A. L. (2018). Closing the sustainability gap: 30 years after «Our Common Future», society lacks meaningful stories and relevant indicators to make the right decisions and build public support. In Ecological Indicators, 87, 193-195. DOI: 10.1016/j.ecolind.2017.12.017.

Korobitsyn, B.A. (2015). Metodicheskij podhod k uchetu istoshcheniya prirodnyh resursov, izmeneniya sostoyaniya okruzhayushchej sredy $i$ chelovecheskogo kapitala $v$ valovom regional'nom produkte [Methodological approach to accounting for the depletion of natural resources, changes in the state of the environment and human capital in the gross regional product], In Ekonomika regiona [Economy of Region], 3(43), 77-88. DOI: 10.17059/2015-3-7.

Kubiszewski, I., Costanza, R., Franco, C., Lawn, P., Talberth, J., Jackson, T., Aylmer, C. (2013). Beyond GDP: Measuring and achieving global genuine progress, In Ecological Economics, 93, 57-68. DOI: 10.1016/j.ecolecon.2013.04.019.

Pearce D. W., Atkinson G. D. (1993). Capital theory and the measurement of sustainable development: An indicator of «weak» sustainability. In Ecological Economics, 8, 103-108. DOI: 10.1016/09218009(93)90039-9 
Porfiriev, B.N. (2016). «Zelenye» tendencii v mirovoj finansovoj sisteme [«Green» trends in the global financial system], In Mirovaya ekonomika i mezhdunarodnye otnosheniya [World Economy and International Relations], 60, 9, 5-16.

Pyzhev, A. I., Gordeev, R. V., Vaganov, E. A. (2020). Reliability and Integrity of Forest Sector Statistics - A Major Constraint to Effective Forest Policy in Russia. In Sustainability, 13(1), 86. DOI: 10.3390/ su13010086.

Pyzheva, Yu.I. (2020). Sustainable development of single-industry towns in Siberia and the Russian Far East: what is the price of regional economic growth? In Journal of Siberian Federal University - Humanities and Social Sciences, 13(4), 582-590. DOI: 10.17516/1997-1370-0591.

Pyzheva, Y. I., Lapo, E. V., Syrtsova, E. A., Pyzhev, A. I. (2021). Evaluation of Genuine Savings in the Russia's far East Regions. In Regional Research of Russia, 11(1), 121-128. DOI: 10.1134/s2079970521010111.

Ryumina, E.V. (2013). Ekologicheski skorrektirovannyj VVP: sfery ispolzovaniya i problemy ocenki [Environmentally Adjusted GDP: Uses and Valuation Issues], In Ekonomika regiona [Economy of Region], 4(36), 107-115. DOI: 10.17059/2013-4-10.

Shirov, A.A. (2020). Statistics for the Benefit of Economics and Society. In Studies on Russian Economic Development, 31, 3-6. DOI: 10.1134/S1075700720010141. 